\title{
Los servicios de igualdad de género. Especial consideración en el ámbito local
}

\author{
M. ${ }^{a}$ Teresa Carballeira Rivera \\ Profesora Titular de Derecho Administrativo \\ Universidad de Santiago de Compostela
}

\begin{abstract}
Sumario: 1. INTRODUCCIÓN. 2. EL VALOR CONSTITUCIONAL DE LA IGUALDAD DE GÉNERO. 2.1. La necesidad de la igualdad. 2.2. La igualdad en la Constitución española. 3. LA PROMOCIÓN DE LAS CONDICIONES DE IGUALDAD REAL. 4. EL REPARTO COMPETENCIAL. 5. ORGANIZACIÓN ADMINISTRATIVA Y ACCIONES POSITIVAS EN FAVOR DE LA MUJER. 5.1. En el ámbito estatal. A) La organización administrativa. B) La articulación de funciones. 5.2. En el ámbito autonómico. A) La organización administrativa. B) La articulación de funciones. 5.3. En el ámbito local. A) La organización administrativa. B) La articulación de funciones.
\end{abstract}

\section{INTRODUCCIÓN ${ }^{1}$}

El presente trabajo tiene como objeto el análisis de la organización y políticas públicas que se están a llevar a cabo en los distintos niveles territoriales para la consecución de la igualdad entre hombres y mujeres. Como es sabido, en nuestra Constitución se dan cita una serie de preceptos que exigen no sólo un reconocimiento formal de la igualdad de todos los ciudadanos sino también una acción decidida de los poderes públicos en pro de la parificación de sexos y la eliminación de conductas discriminatorias.

Así pues, una de las vertientes de este reconocimiento de la igualdad y la prohibición de toda discriminación por razón de sexo es el deber de articular acciones positivas en beneficio de determinados colectivos sociales. Esta vertiente es tanto más importante cuanto más histórico es el desequilibrio que se pretende corregir. Y tanto menos necesaria cuanto más efectiva y plástica sea esa igualdad. De éstas y su forma de articulación trataremos en las páginas siguientes.

\section{EL VALOR CONSTITUCIONAL DE LA IGUALDAD DE GÉNERO}

\subsection{La necesidad de la igualdad}

La realidad española que nos toca vivir es el producto de un enorme cambio que se ha venido pergeñando desde los años setenta. Arrastrando

\footnotetext{
${ }^{1}$ El presente trabajo se inserta en el Proyecto de investigación nacional BJU2003-01752 y en el PGIDIT03CS020203PR de la Comunidad Autónoma de Galicia, de los que es Director principal el Prof. D. José Luis Carro Fernández-Valmayor.
} 
una historia jurídica cargada de desequilibrios, únicamente atemperados por medidas de corte proteccionista, hemos ido recorriendo un largo camino en el que, poco a poco, se han ido depurando muchos de los obstáculos que arremetían cual ariete contra la dignidad de las personas que proclama el art. $10 \mathrm{CE}$. Aún así la meta no se ha alcanzado. La constatación de los datos extraídos de nuestro pasado más inmediato justifica sobradamente la necesidad de llevar a cabo acciones positivas en favor de los grupos más desprotegidos de la sociedad, significadamente de las mujeres.

Ejemplos de esta realidad desigualitaria podrían ser las siguientes cifras del territorio español. En términos globales, el $51 \%$ de la población española son mujeres. En la Unión Europea son el 51,22\%. Este hecho y la evolución sociodemográfica previsible está obligando a una redefinición de las relaciones de sexos y la inclusión del sector femenino en todas las facetas de la vida social. Las mujeres no son una minoría ni un grupo especial sino una colectividad integrada en la sociedad y formando parte activa de ella.

En materia de empleo, según la Encuesta de población activa de $2004^{2}$, la tasa de empleo femenino es del 38,6 \% frente al 62,6 \% masculino. A estos datos ha de añadirse que el peso del sector servicios acapara la mayor parte del empleo femenino y la diferencia retributiva entre hombre y mujeres alcanza en España el 28,88 \% siendo la contratación temporal la fórmula más habitual de integración en el mundo laboral de la población femenina.

Si tomamos como referencia la forma de acceso al empleo, la objetivación de las pruebas favorece la presencia de la mujer en el mundo laboral. Así, hay más mujeres ocupadas en el sector público que en el privado (2,27 puntos por encima del hombre), si bien en el nivel A de la función pública la presencia de la mujer representa un $35,21 \%$ respecto del total, mientras que en el nivel D el 73,62 \%. En cuanto a los cargos públicos, el porcentaje de mujeres que ostentan cargos en la Administración civil es del 22,3\%. Sin embargo, en el ámbito parlamentario (36\%) y judicial $(41,89 \%)$, la proporción se torna más equilibrada respecto del hombre.

En materia de marginación y malos tratos, la violencia doméstica se centra prácticamente en la mujer como víctima, cifrándose en 40.518 las denuncias presentadas por delitos en el año 2004.

2 Datos tomados de «La mujer en cifras» del Instituto de la Mujer del Ministerio de Trabajo y Asuntos Sociales. 
En cuanto a la educación, el porcentaje de mujeres que carecen de estudios es del 10,43\% frente al 7,75\% de hombres. Dicho dato contrasta, no obstante, con el peso creciente de la mujer en el ámbito universitario, centrado en las licenciaturas del área de salud, humanidades y ciencias jurídicas y sociales.

En el ámbito familiar, la mujer dedica aproximadamente el doble de tiempo que el hombre a las tareas domésticas $(7,22$ horas y 3,10 horas respectivamente). También se ha experimentado un aumento notable de las familias monoparentales femeninas a raíz de la ley del divorcio.

Una brecha de tan o mayor importancia que las descritas es la falta de integración de la mujer en el movimiento asociativo social y político (partidos, sindicatos, asociaciones, círculos intelectuales, etc.). Esta situación obedece fundamentalmente a dos razones. Una de carácter exógeno, plasmada en la falta de líderes que sepan transmitir la ideología e identificarse con este sector de la población; y otra de carácter endógeno, la propia estrategia femenina para facilitar su inserción en el tejido social sin riesgo de encontrar rechazo a algunas connotaciones ideológicas de corte feminista consideradas socialmente peyorativas. Temas todos que aún no han sido abordados por ninguna política de promoción de la igualdad de la mujer.

Toda esta situación es consecuencia, en gran medida, del mantenimiento a nivel social de estereotipos tradicionales que siguen vigentes en el imaginario colectivo español. Así, continúan perviviendo en el rol familiar consignas como «la madre debe pedir permiso en el trabajo para cuidad al niño enfermo», «la mujer debe apoyar a su marido en su carrera», «la maternidad es la mayor fuente de satisfacción de una mujer», o «es más desagradable oír tacos en una mujer que en un hombre». Dentro del rol laboral afloran consignas como: «cuando la mujer accede mayoritariamente a una profesión ésta comienza a perder prestigio», «la mujer se masculiniza en el trabajo», «la mujer está más preocupada por la seguridad laboral que por la originalidad en el trabajo». Y respecto de las tareas extradomésticas: «La mujer ha de dirigir el hogar y el hombre los negocios», «El hombre tiene la responsabilidad última de ganar el sustento», «La mujer no debe trabajar cuando puede vivir bien del sueldo de su marido», o, en fin, «para una madre la vida profesional debe estar subordinada a la familiar $\rangle^{3}$.

\footnotetext{
${ }^{3}$ M. Álvaro Page, M. Fuente SÁnchez, y Aranda Jaquotot, M.T., «La evaluación de los planes de igualdad de oportunidades entres mujeres y hombres (PIOM) del Instituto de la Mujer: referencia obligada al segundo de ellos», en Evaluación de las políticas de igualdad, 24, Instituto de la Mujer, Madrid, 1999, p. 106 y ss.
} 
En definitiva, según los resultados de la evaluación del II PIOM ${ }^{4}$, la mujer sigue estando a gran distancia (tres veces más) del hombre en calidad de vida y en consolidación de una determinada situación social. Su grado de autonomía y de tiempo libre es inferior y el salto del mundo académico al laboral aún resulta difícil. Por otra parte, el acceso de la mujer a los puestos de dirección en la carrera administrativa y privada continúa chocando con tres grandes obstáculos materiales -los horarios y su compatibilidad con las cargas familiares, la maternidad, y la movilidad geográfica que supone el acceso a algunos puestos- $\mathrm{y}$ un paquete nada despreciable de prejuicios sociales. A cambio, la incorporación de las mujeres al mundo educativo a través de los cursos de formación ha sido muy fructífera alcanzándose un mayor nivel formativo y una trama de relaciones sociales que aportan una gran satisfacción personal. En suma, todo esto nos sigue recordando el importante papel que aún toca cumplir a los poderes públicos, mediante una labor continuada y firme, en aras de la igualdad real de sexos.

\subsection{La igualdad en la Constitución española}

Desde el punto de vista jurídico, la referencia de las políticas de promoción de la igualdad en España encuentra su anclaje en dos fuentes: desde la perspectiva supranacional en los Tratados de la UE, significadamente el Tratado de Amsterdam de 1997 y la futura Constitución europea; y desde la perspectiva interna en los artículos 9 y 14 CE.

En nuestra Constitución, la igualdad es, ante todo, un principio jurídico y como tal opera no sólo en el campo de la igualdad formal sino también en el de la igualdad real o sustancial ${ }^{5}$. De entrada, el art. 1.1 CE consagra la igualdad en un sentido principial, esto es, como una idea que subyace a toda la estructura constitucional y a todo el ordenamiento ${ }^{6}$. Allí se dice que España es un Estado social y democrático de derecho «que propugna como valores superiores de su ordenamiento jurídico la libertad, la justicia, la igualdad y el pluralismo político». Con esta declaración, a la que si bien no se le ha otorgado por la jurisprudencia constitucional valor positivo alguno, sí se le ha

\footnotetext{
4 Idem, p. 95 y ss.

5 Para una aproximación actualizada al principio de igualdad, veáse A. PALOMAR OLMEDA, «El principio de igualdad y la interdicción de la discriminación por razón de sexo desde una perspectiva constitucional», en El tratamiento del género en el ordenamiento español, Tirant lo Blanch, Valencia, 2005, p. 23 a 133.

6 F. Rubio Llorente, «La igualdad en la jurisprudencia del Tribunal Constitucional», REDC, n. 31,1991, p. 9.
} 
reconocido el mérito de ser la piedra basilar del ordenamiento y el lema de la actuación de los poderes públicos al dirigir su labor hacia la culminación de esos valores ordenadores del Estado que, en esa medida, ejercen un poder transformador de la realidad. Como señala RUBio LlORENTE, el principio de igualdad «ni agota su eficacia en el ámbito puramente jurídico ni, dentro de él, puede ser considerado como una realidad estática desde la cual hayan de interpretarse las normas existentes, o deducir, a falta de ellas, la regla de decisión para el caso concreto, por la buena y simple razón, entre otras, de que es un mandato dirigido al legislador, es decir, al creador ordinario de las normas jurídicas» $»^{7}$. En ese sentido, la igualdad debe impregnar todo el ordenamiento jurídico y guiar la evolución del Estado en su conjunto. Es, siguiendo el símil comunitario, el mainstreaming, el elemento transversal del Estado español.

Pero la virtualidad del principio de igualdad no se agota en lo expuesto. Tiene, a decir de un nutrido sector doctrinal, otro valor añadido, un plusvalor informador. La proclamación constitucional de la igualdad como valor superior implica, como apunta López Guerra «conceder al criterio igualitario un peso más fuerte que a criterios derivados de otros intereses o valores no específicamente primados en el art. 1.1 CE» ${ }^{8}$. De esta suerte, la interpretación tendencial de todo el sistema jurídico en beneficio de la igualdad cobra carta de naturaleza propia y se erige en clave del funcionamiento de las organizaciones públicas y criterio dirimente de la constitucionalidad de las normas.

Por su parte, el art. $14 \mathrm{CE}$ se encarga de dotar de fuerza jurídica a este valor superior diciendo, en sentido positivo, que «los españoles son iguales ante la ley», y, en sentido negativo, que no puede prevalecer «discriminación alguna por razón de sexo». De este modo, el principio de igualdad adquiere una veste jurídica concreta que no es sino su manifestación como derecho subjetivo individual, fundamental y protegible en vía de amparo frente a la desigualdad en la ley y en aplicación de la ley.

El artículo 14 CE supone el deber de garantizar la igualdad a través de la prohibición de discriminaciones directas o generadoras de un trato perjudicial en función de la pertenencia a un determinado grupo; e indirectas, esto es, aquellas que dan tratamientos indiferenciados a situaciones de base netamente diferentes. Estas prohibiciones, inmanentes del derecho fundamental, no deben hacerse depender de las coyunturas políticas ni aplicarse a cualquier grupo social. Son prohibiciones absolutas y permanentes aplicables a aquellos grupos sociales que, por experiencia histórica son víctimas de una

\footnotetext{
7 Rubio Llorente, cit., p. 11.

${ }^{8}$ L., LÓPEZ GuERRA, «Igualdad, no discriminación y acción positiva en la Constitución», en Mujer y Constitución en España, Centro de Estudios Políticos y Constitucionales, Madrid, 2000, p. 22.
} 
profunda y arraigada hostilidad, marginación o discriminación social ${ }^{9}$. El art. $14 \mathrm{CE}$ es, en definitiva, la consagración de un derecho a la igualdad formal. Como expresa magníficamente el Tribunal Constitucional, la virtualidad del artículo $14 \mathrm{CE}$ «también persigue la interdicción de determinadas diferencias, históricamente muy arraigadas, que tanto por la acción de los poderes públicos como por la propia práctica social, han situado a amplios sectores de la población en posiciones no sólo desventajosas sino abiertamente contrarias a la dignidad de la persona que reconoce el art. 10 de la Constitución» (STC 19/1989, de 31 de enero, f.j. 4).

Junto a este reconocimiento fundamental, la Constitución ofrece un tercer pilar al derecho a la igualdad, la búsqueda de la igualdad material o real. Es notorio que la igualdad formal puede tener un efecto perverso cuando se aplica a situaciones enquistadas de desigualdad en el sentido de llegar a convertirse en un instrumento de conservación del statu quo ante que en un elemento de cambio y desarrollo del equilibrio. Estas consideraciones tienen fiel reflejo cuando de igualdad entre sexos se trata. Como dice Rey MARTíneZ ${ }^{10}$, « la adopción de un derecho neutro no es una decisión neutral», esto es, cuando un derecho formalmente igualitario se enfrenta a una situación de desequilibrio social entre sexos, su resultado es históricamente desequilibrador, incapaz de desempeñar la función de igualación que se le pide. Arrastra siempre un efecto perverso, cual es el de conceder ventaja al que más ventaja tiene de partida. Por eso, la parificación entre los sexos permite «el establecimiento de un derecho desigual igualatorio». (STC 229/1992, de 14 de diciembre, f.j. 2).

En apoyo de esta nueva acepción de la igualdad viene el art. 9.2 CE. En él se obliga a los poderes públicos a promover «las condiciones para que la libertad y la igualdad del individuo sean reales y efectivas». Se configura así un deber de prosecución efectiva ordenando a los poderes públicos a utilizar sus potestades en la procura de una sociedad más igualitaria y a desarrollar acciones en ese sentido. El art. 9.2 CE supone, en realidad, desde la perspectiva de la discriminación por razón de sexo, «no sólo la interdicción de la desigualdad de trato injustificada sino también la decisión constitucional de acabar con la histórica situación de inferioridad atribuida a la mujer en la vida social» (STC 19/1989, f.j. 4). Exige una igualdad más allá de la letra legal, una igualdad que tiene que manifestarse en un cambio real y tangible en la sociedad y sus valores.

\footnotetext{
9 F. REY MARTíneZ, «El principio de igualdad y el derecho fundamental a no ser discriminado por razón de sexo», La Ley, n. ${ }^{\circ}$ 4984, 3 de febrero de 2000, p. 1721.

10 F. Rey MartíneZ, cit., p. 1722.
} 
Asi pues, los promotores de este cambio, en especial, el legislador y la Administración, habrán de adoptar las medidas adecuadas en un corto plazo de tiempo para erradicar tal situación de discriminación so pena de la tacha de inconstitucionalidad de los actos que la alimentan. Y es que la Constitución, como dice el Alto Tribunal, «exige de los poderes públicos enfrentados a una situación de desigualdad de origen histórico, la adopción de una actitud positiva y diligente tendente a su corrección; de tal modo que, si bien no cabe, por lo general, mesurar ex Constitutione la falta de celo y presteza del legislador en la procura de aquella corrección cuando una desigualdad de hecho no se traduce en una desigualdad jurídica, la concurrencia de esta última por la pervivencia en el ordenamiento de una discriminación no rectificada en un lapso de tiempo razonable habrá de llevar a la calificación como inconstitucionales de los actos que la mantengan» (STC 216/1991, de 14 de noviembre, f.j. 5).

\section{LA PROMOCIÓN DE LAS CONDICIONES DE IGUALDAD REAL}

Entre las medidas a adoptar por los poderes públicos para la erradicación de un trato discriminatorio de la mujer se encuentran las comúnmente denominadas acciones positivas. El fin de las mismas es «contribuir a poner fin a una situación de inferioridad en la vida social y jurídica, caracterizada por la existencia de numerosas trabas de toda índole» (STC 16/1995, de 24 de enero, f.j. 3). Se justifican así, todo tipo de medidas destinadas a remover obstáculos que impidan la realización de la igualdad de sexos tales como la creación de «situaciones de ventaja» o «las medidas de apoyo hacia la mujer» (STC 229/1992, de 14 de diciembre, f.j. 2).

Las acciones positivas pueden revestir distintas formas. Interesa ahora examinar las denominadas medidas compensadoras o medidas de acción positiva en sentido estricto, como acostumbra denominar la alta jurisprudencia y la doctrina mayoritaria. Son aquellas estrategias y políticas públicas elaboradas por los niveles gubernamentales y articuladas por la Administración pública que tienen como fin acelerar la equiparación de facto entre la mujer y el varón y auxiliarla en su marcha hacia la igualdad. Nos estamos refiriendo a ese paquete de acciones públicas de vocación equilibradora, surgidas al abrigo del Estado Social y que tratan de imprimir un cambio en los valores sociales a favor de la igualdad de sexos.

Por su naturaleza, tales medidas gozan de las siguientes características: 
a) Son politicas de apoyo impuestas por y desde el texto constitucional $y$, en ese sentido, irrenunciables en su articulación. Dado que inciden en la virtualidad misma de un derecho fundamental, su puesta en práctica no puede quedar sometida al albur de las coyunturas financieras o políticas de cada momento. No son tanto una opción tendencial de los poderes públicos al estilo de las acciones recogidas en el art. 53.3 CE como una efectiva obligación que permanece en el tiempo hasta en tanto la realidad social deje constancia de su innecesariedad.

b) Tienen carácter genérico. Van dirigidas a un grupo singularizado de sujetos en cuanto tal, esto es, a las mujeres como sector social que padece una situación de desventaja ancestral que no obedece a su concreta naturaleza o aptitud. Su objetivo primordial no reside en apoyar a sujetos concretos sino en conseguir el reequilibrio social eliminando los obstáculos que impiden al grupo colocarse en una situación de paridad con el resto de la sociedad. Y, finalmente.

c) Gozan de carácter general y neutro. Las medidas compensadoras nunca implican colocar en una posición de preeminencia a determinados grupos respecto del resto de la sociedad ni priman situaciones concretas de sus miembros en ámbitos específicos. Únicamente arrastran el efecto de otorgar un tratamiento político especial y la puesta en pie de diferentes estrategias públicas con el fin de lograr la igualación real, sin que en tal proceso se generen perjuicios o desventajas para el resto de los ciudadanos.

Desde una perspectiva material, este tipo de acciones suelen ir enfocadas a la erradicación de la discriminación en su faceta más primaria, como son la lucha contra la violencia de género, el acceso al empleo o la educación de la mujer. Junto a ellas, es habitual encontrar otras áreas de actuación más sectoriales como la salud, marginación, el acceso al poder o el asociacionismo. Si tenemos en cuenta las demandas manifestadas por la población femenina española los temas relativos a malos tratos y violencia doméstica constituyen el área prioritaria de atención pública sobre el que existe una anuencia absoluta. No así en el ámbito de la formación y el empleo, donde sólo la población femenina más joven muestra mayores inquietudes sobre la materia. Tras éstas, las acciones de formación y capacitación profesional de la mujer y la ayuda a mujeres en grave situación económica o de marginación, centran la atención del sector. Las restantes políticas de promoción de la igualdad, se consideran, por lo general, un tema secundario, no tanto porque se desestime su importancia sino porque se demanda primeramente la solución de aquellas situaciones más graves o necesitadas. 


\section{EL REPARTO COMPETENCIAL}

Todo lo dicho anteriormente nos lleva a una conclusión evidente y es que las acciones positivas a favor de la igualdad de hombres y mujeres es una tarea que incumbe a todos los poderes públicos y a todos los niveles territoriales.

La traslación de este deber público general no tiene, sin embargo, correlato en el nivel competencial. Efectivamente, si analizamos los arts. 148 y $149 \mathrm{CE}$ observaremos que no existe ningún título competencial por el que se otorgan competencias a los entes territoriales en esta concreta materia. Sin embargo, ello no quiere decir que se trate de una materia sobre la que no existe posibilidad de ejercicio o actuación responsable. Antes bien, por todo lo antedicho es evidente que la procura de la igualdad de oportunidades entre hombre y mujer tiene anclaje no sólo en la cláusula de Estado social sino en la de Estado de derecho en la medida en que el fin perseguido, la igualdad real de hombre y mujeres se construye desde un valor preeminente de la Constitución, los derechos fundamentales y un principio rector, el principio de igualdad recogido en el art. 1.1 CE.

Por su parte, el art. 9.2 CE hace un encargo expreso a todas las Administraciones territoriales de adoptar las medidas que sean necesarias para que la igualdad sea real y efectiva. De ahí que haya de entenderse que estamos ante una obligación impuesta a todos los niveles territoriales en lo que atañe a su observancia, respeto y promoción. Así pues, desde el punto de vista estrictamente constitucional, se trata de una competencia indistinta, sin atribución formal expresa en los artículos distribuidores y ejercitativa por todos los niveles territoriales con carácter imperativo.

A estas consideraciones responde la asunción de competencias que en esta materia han efectuado expresamente algunos Estatutos de Autonomías. O las atribuidas a los entes locales en virtud del art. 28 LBRL. En él se dice que los municipios podrán realizar actividades complementarias a las competencias atribuidas al Estado y Comunidades Autónomas, especialmente en materia de promoción de la mujer. Esta complementariedad de la que habla el art. 28 LBRL hay que entenderla en un sentido amplio ya que se trata de un ámbito en el que los municipios pueden y deben tener su propio margen de actuación, toda vez que el cumplimiento de los dictados constitucionales les vincula en igual medida y su condición de Administración próxima al ciudadano ofrece una plataforma de excepción para la eficaz ejecución de este tipo de políticas públicas. Como bien apunta el actual borrador del Libro Blanco de la Gobernanza 
que ha redactado el Gobierno estatal, tal precepto debe abrir «interesantes expectativas de flexibilidad en al asunción de competencias municipales, toda vez que habilitan a los ayuntamientos a intervenir ante nuevas demandas de los ciudadanos o ante nuevas demandas sociales no previstas por el legislador y no cubiertas por la acción de las demás administraciones públicas». Pese a todo, la carencia de una ley sectorial específica en materia de igualdad de sexos en casi todos los ámbitos territoriales superiores - a excepción del País Vasco con su reciente Ley 4/2005, de 18 de febrero, para la igualdad de mujeres y hombres- compromete de forma severa la capacidad de actuación de los entes locales que, en este sentido, ven prácticamente secuestrado su poder de resolución política por las acciones y competencias autonómicas y la técnica subvencional, amén de la falta de recursos económicos y medios personales cualificados. Sería por tanto, deseable que las potencialidades que ofrece el ámbito local en la articulación de este tipo de medidas compensadoras quedase perfectamente garantizadas a través de un reparto racional de competencias y la correspondiente asignación de medios financieros.

En definitiva, desde el punto de vista vertical, todas las Administraciones territoriales gozan de competencias en materia de promoción de políticas de igualdad de la mujer en su respectivo ámbito y todas están facultadas para diseñar su política propia en la materia y dentro del marco de la legalidad vigente, estatal, comunitaria e internacional. Y, desde el punto de vista sustantivo, se trata de una competencia abocada a la transversalidad, esto es, debe operar desde la horizontalidad sobre todas las materias asumidas por los distintos entes territoriales. De modo que, la procura de la igualdad de sexos se ha de configurar como una premisa de actuación y articulación de las restantes políticas públicas.

\section{ORGANIZACIÓN ADMINISTRATIVA Y ACCIONES POSITIVAS EN FAVOR DE LA MUJER}

Para la articulación de estas competencias se han utilizado distintas fórmulas organizativas que responden igualmente al grado de desarrollo y sensibilidad de la Administración en cuestión. Podemos distinguir, por tanto, tres niveles de actuación en el campo de la igualdad de sexos coincidentes con cada uno de los ámbitos territoriales y varios subniveles en función del tipo de organización establecida. 


\subsection{En el ámbito estatal}

\section{A) La organización administrativa}

Para dar cumplimiento a los objetivos de igualdad en el ámbito estatal se creó el Instituto de la Mujer. Tipológicamente, se trata de un Organismo autónomo, con personalidad jurídica propia, adscrito al Ministerio de Trabajo y Asuntos Sociales, que tiene como fin legal «promover y fomentar las condiciones que posibiliten que la igualdad social de ambos sexos y la participación de la mujer en la vida política, cultural, económica y social». Fue creado por Ley 16/1983, de 24 de octubre y la regulación actual se contempla en el RD 774/1997, de 30 de mayo.

Su actividad, inspirada en el lema de la transversalidad, va dirigida a la realización de las siguientes funciones estatales: estudio de la situación de la mujer en el campo legal, educativo, cultural, sanitario y sociocultural; recopilación de información sobre la situación de la mujer; elaboración de informes e impulso de medidas de promoción; establecimiento de relaciones con organizaciones no gubernamentales; $y$, canalización de ayudas y fomento de la prestación de servicios a favor de la mujer, especialmente de las más necesitadas.

Evidentemente, el hecho de que el grueso de las políticas estatales de igualdad se concentren en el Instituto de la Mujer no obsta para que desde los restantes órganos del gobierno estatal se promuevan otro tipo de acciones positivas y legales apoyándose en el lema de la transversalidad. Tal es el caso del reciente «Acuerdo por el que se adoptan medidas para favorecer la igualdad entre hombres y mujeres» aprobado por el Consejo de Ministros el 4 de marzo del 2005, en materia de empleo, empresa, conciliación de la vida laboral y familiar, investigación, solidaridad, deporte y violencia de género. Su puesta en marcha y desarrollo se encomienda al Ministerio de Trabajo y Asuntos sociales, a través de la Secretaría General de Políticas de la Igualdad. Tales medidas se enmarcan dentro de una estrategia pública estatal de la que también forma parte el Libro Blanco de la Dependencia, que apunta una serie de medidas tendentes a evitar la discriminación femenina, y la futura Ley de igualdad y de conciliación de la vida familiar y laboral. E, igualmente, el «Plan para la igualdad de género en la Administración General del Estado», de idéntica fecha, en el que se incluye un importante abanico de acciones positivas para favorecer la promoción de las mujeres a puestos de mayor categoría, asegurar la conciliación de sus responsabilidades profesionales con su vida personal y familiar y promover la cultura de corresponsabilidad entre ambos sexos. 


\section{B) La articulación de funciones}

El funcionamiento de este Instituto sigue la técnica planificadora trienal o cuatrienal, estando vigente en la actualidad el IV Plan para la Igualdad de Oportunidades entre Mujeres y Hombres 2003-2006 aprobado el 7 de marzo de 2003 por el Consejo de Ministros (I Plan, 1988-1990; II Plan 1993-1995; III Plan 1997-2000). Para su confección se han tenido en cuenta tanto las recomendaciones internacionales y comunitarias, especialmente la Estrategia Marco Comunitaria sobre igualdad, como la realidad social española aportada por los diferentes Agentes sociales, Organizaciones no gubernamentales y Administraciones públicas. Podemos señalar como ejes de la planificación estatal los siguientes:

a) Desarrollar medidas específicas dirigidas a combatir las discriminaciones por sexos.

b) Mejorar la presencia de las mujeres en todos los ámbitos de la vida social.

c) Desarrollar el principio de transversalidad.

d) Articular mecanismos de cooperación entre los distintos operadores jurídicos y sociales para la consecución de los objetivos de igualdad.

Las áreas temáticas de actuación se han ido reduciendo progresivamente y focalizándose en temas puntuales que exigen una mayor actuación en función de las características sociales y la propia evolución de las políticas de igualdad. En la actualidad el IV Plan contempla las siguientes áreas prioritarias: articulación de la transversalidad de género, vida laboral y empleo, participación en la toma de decisiones, promoción de la calidad de vida, fomento de la igualdad en la vida civil, transmisión de valores y actitudes igualitarias, conciliación de la vida familiar y laboral y cooperación interadministrativa. Cada área, integrada por las correspondientes iniciativas, se desarrolla a través de programas de objetivos que a su vez se desglosan en acciones y proyectos concretos de ejecución.

En líneas generales cabe destacar como hitos más relevantes hasta la fecha las acciones llevadas a cabo en el ámbito laboral y social. En materia de empleo destacan los programas destinados a la formación ( tales como los de acceso directo INNOVA, CLARA, Formación profesional ocupacional o C-Test sobre formación en nuevas tecnologías), el proyecto ISOS, incardinado en la Estrategia Marco Comunitaria sobre igualdad, dirigido al estudio de las diferencias salariales entre hombre y mujer y la 
valoración de los puestos de trabajo. O el proyecto PROMOCIONA creado para analizar y reducir los desequilibrios de género y segregación.

En el marco empresarial, conviven los de carácter económico para el fomento de la actividad empresarial («Emprender en femenino», Programa de microcréditos para empresarias y emprendedoras) junto con los de contenido formativo (Programa de formación de gestión empresarial o de gestión para empresarias y emprendedoras), y los de asesoramiento (Programa de apoyo empresarial). De entre ellos destaca por la originalidad de su fin y la incidencia en el ámbito empresarial privado el programa OPTIMA, realizado en colaboración con otras instituciones, para favorecer la presencia de la mujer en la empresa privada a través de la implantación de acciones positivas en las empresas adheridas (32 hasta ahora). Cerrando este abanico se encuentran los programas dirigidos a responsables de políticas de empleo y personal técnico o los generales de sensibilización y difusión (folletos, carteles, videos y exposiciones de carácter divulgativo).

Dentro del ámbito social se han venido elaborando hasta recientes fechas programas integrales de atención sanitaria a la mujer, educativos y de exclusión social que en la actualidad no tienen continuidad. No así en el ámbito de la imagen y medios de comunicación donde sigue ocupando un lugar relevante el «Observatorio de la Publicidad», creado para denunciar la publicidad sexista y modificar los patrones culturales. A su través se abre la posibilidad de negociación o actuación de oficio contra los medios y empresas que transmitan una imagen discriminatoria de la mujer. En el año 2003 se atendieron 654 denuncias con un total de 177 campañas denuncias. En esta misma línea se mueve el Observatorio de la igualdad de oportunidades, creado en el año 2000.

Por último, la violencia de género sigue ocupando un lugar preponderante entre las políticas de la igualdad del Instituto de la Mujer, destacando su participación en el II Plan integral contra la violencia doméstica que culminó en el año 2004. Sus áreas de actuación se centraron en la adopción de medidas preventivas y de sensibilización, plasmadas básicamente en campañas publicitarias, la promoción de medidas legislativas y judiciales, y la adopción de programas asistenciales y de intervención social con el fin de prestar atención sanitaria y psicológica a los colectivos afectados y crear una infraestructura apta para dar cobertura a las necesidades de las víctimas. También se incluyeron programas de formación de personal directamente involucrado en este sector (jueces, policías, asistentes sociales, forenses, medios de comunicación, etc.). 


\subsection{En el ámbito autonómico}

\section{A) La organización administrativa}

Por lo general la mayoría de las Comunidades Autónomas han optado por establecer algún tipo de organización para atender estas obligaciones. Doce de ellas han apostado por dar cierta autonomía a la organización creando los correspondientes Organismos autónomos a la hechura estatal: los Institutos. Son Galicia ${ }^{11}$, Asturias ${ }^{12}$, Castilla-La Mancha ${ }^{13}$, Murcia ${ }^{14}$, Navarra $^{15}$, Andalucía ${ }^{16}$, Cataluña ${ }^{17}$, País Vasco ${ }^{18}$, Islas Baleares ${ }^{19}$, Canarias $^{20}$, Aragón $^{21}$ y Extremadura ${ }^{22}$.

Las restantes, en cambio, no han creado ninguna organización diferenciada para llevar a cabo las tareas de acción positiva a favor de la mujer, integrándolas en Direcciones Generales o Secretarías de las Consejerías competentes en materia de bienestar y servicios sociales. Son Madrid ${ }^{23}$, Castilla-León $^{24}$, Valencia ${ }^{25}$, Cantabria ${ }^{26}$ y La Rioja ${ }^{27}$.

${ }^{11}$ Ley 3/1991, de 14 de enero, de creación del Servicio Gallego de Promoción de la Igualdad del Hombre y de la Mujer.

12 Decreto 137/1999, de 16 de septiembre, por el que se regula la organización y funciones del Instituto Asturiano de la Mujer.

${ }^{13}$ Ley 22/2002, de 21 de noviembre, de creación del Instituto de la Mujer Castilla-La Mancha.

${ }^{14}$ Ley 12/2002, de 3 de diciembre, de creación del Instituto de la Mujer de Murcia.

15 Decreto Foral 398/ septiembre, por el que se regula la organización y funciones del Instituto Navarro de la Mujer.

${ }^{16}$ Ley 10/1998, de 29 de diciembre, por el que se crea el Instituto de la Mujer de Andalucía.

${ }^{17}$ Ley 11/1989, de 10 de julio, de creación del Instituto Catalán de la Mujer.

${ }^{18}$ Ley 2/1988, de 5 de febrero, sobre creación del Instituto Vasco de la Mujer.

${ }^{19}$ Ley $5 / 2000$,de 20 de abril, del Instituto Balear de la Mujer.

${ }^{20}$ Ley 1/1994, de 13 de enero, sobre creación del Instituto Canario de la Mujer.

${ }^{21}$ Ley 2/1993, de 19 de febrero, por la que se crea el Instituto Aragonés de la Mujer.

${ }^{22}$ Ley 11/2001, de 10 de octubre, de creación del Instituto de la Mujer de Extremadura.

${ }^{23}$ Ley 3/1993, de 2 de abril, de creación del Consejo de la Mujer.

${ }^{24}$ Decreto 162/1999, de 29 de julio, de modificación parcial de las estructuras orgánicas de las Consejerías de Castilla y León.

${ }^{25}$ Decreto 120/2003, de 11 de julio, por el que se aprueba el reglamento orgánico y funcional de la Consellería de Bienestar Social.

${ }^{26}$ Decreto 198/2003, de 18 de diciembre, por el que se modifica la estructura orgánica de la Consejería de Relaciones institucionales y Asuntos europeos, y Ley 6/2002,d e 10 de diciembre.

27 Decreto 36/2003, de 15 de julio, por el que se establece la estructura orgánica de la Consejería de Juventud, Familia y Servicios Sociales. 


\section{B) La articulación de funciones}

En cuanto a sus funciones, no distan mucho de las descritas a nivel estatal. Siguiendo la evolución de estas instituciones, podría decirse que los frentes sobre los que actúan son de tres tipos: prestación de servicios de información y asesoramiento; tareas de apoyo al asociacionismo y movimientos sociales pro igualdad; y actuación sobre áreas temáticas concretas.

Por lo que respecta a las técnicas de actuación, sólo algunas de las Comunidades Autónomas se adscriben al modelo de planificación general trienal, acompañadas de los correspondientes programas y proyectos. En la actualidad cuentan con algún Plan integral para la igualdad de oportunidades el País Vasco, Galicia, Extremadura, Canarias, Cantabria, Madrid y Castilla León. Las restantes utilizan la planificación sectorial o simplemente realizan actuaciones puntuales en temas que se consideran de interés prioritario.

En cuanto a las áreas de actuación, es de destacar la escasez de medios y la incidencia sobre temas de carácter básico como la violencia, educación y empleo y la consiguiente dejación de áreas como deporte, investigación, calidad de vida, sectores femeninos marginales, cohesión de programas y objetivos, así como los ámbitos del poder y la participación social y familiar de la mujer.

En general, políticas de acción positiva autonómicas corren parejas a las realizadas a nivel estatal y europeo. Y muchas de las acciones puestas en práctica son fruto de convenios puntuales entres éstas y las instituciones superiores (programas EQUAL, NOW, NOVA, proyectos CLARA, PROMOCIONA, OPTIMA, ELAS, etc.). Así, encontramos en casi todas una gran preocupación por el empleo, la reinserción laboral y la actividad empresarial que se manifiestan en múltiples acciones. Es el caso del País Vasco, Andalucía y Galicia con su colaboración en el programa OPTIMA destinado a otorgar distintivos de calidad a las empresas privadas que realicen un plan de acción positiva. Navarra, quien además de participar en aquél cuenta con los programas «A por más» dirigido a la consolidación de la mujer empresaria, Equal-Pilnar y Equal-Técnica derivado del programa europeo del mismo nombre destinado a la inserción en el mercado laboral en sectores infrarepresentados. Canarias con el proyecto Ariadna, destinado a reducir los desequilibrios de género en materia de empleo. Galicia con el proyecto Promociona, en colaboración con el Instituto de la Mujer para la creación de sistemas locales de igualdad de oportunidades. O, en fin, Cantabria con Equal-Gema destinado a actualizar el observatorio de la discriminación laboral. 
Junto a ellos conviven otros destinados a la prevención y erradicación de la violencia doméstica, que constituyen el núcleo fuerte de la actuación autonómica. Por regla general, las acciones integradas en esta materia van dirigidas a la consecución de tres grandes objetivos: a) la prevención y estudio de las causas de la violencia de género; b) la atención a mujeres que han sufrido malos tratos; y, c) la inserción socio-laboral de las víctimas de la violencia. Casi todas las Comunidades Autónomas cuentan con algún plan general para luchar contra la Violencia hacía la mujer cuyas líneas estratégicas se desarrollan a través de programas específicos tales como el CUALIFICA de Andalucía, destinado a la formación y empleo de las víctimas de la violencia o el Programa de hombres maltratadores que lleva adelante la Comunidad de La Rioja.

Otro de los ejes de actuación que se está abriendo camino en el ámbito autonómico, aunque a gran distancia de los anteriores, es el de la implantación de la transversalidad de las políticas de género. A este respecto, merece una especial mención por su carácter innovador el Proyecto polito sobre género y presupuestos públicos que se viene ejecutando en el País Vasco desde el año 2002 y cuyo fin consiste en integrar los objetivos de igualdad en el reparto de los fondos públicos entre las distintas Administraciones vascas. También el Programa de la unidad de igualdad y género de la Comunidad Autónoma andaluza, que persigue consolidar la transversalidad en el quehacer público ofreciendo apoyo y formación específica a los planificadores y gestores de las políticas públicas autonómicas. Y la Estrategia regional para la igualdad de oportunidades de Castilla y León, entre cuyas acciones se contempla la creación de un órgano interadministrativo, la Comisión interconsejerías para la igualdad de oportunidades entre mujeres y hombres, que tiene como objetivo principal incorporar los criterios de género en las políticas regionales.

Finalmente, en el campo de la conciliación de la vida familiar y laboral comienzan a despuntar las primeras líneas de actuación autonómica como sucede en Cataluña con el programa Equal-Compartir o en las Comunidades Autónomas de Madrid y Cantabria que incluyen por primera vez acciones en esta materia dentro de los correspondientes Planes de igualdad de oportunidades entre mujeres y Hombres.

\subsection{En el ámbito local}

Pese al innegable papel que cumplen los entes locales en esta materia dada la proximidad entre el sustrato social y este nivel organizativo, apenas existen estudios que nos permita definir exhaustivamente las líneas 
estratégicas seguidas por los municipios en materia de igualdad de la mujer. Este vacío únicamente queda salvado por la Encuesta llevada a cabo por la Federación Española de Municipios y Provincias en colaboración con el Instituto de la Mujer estatal en el año $2001^{28}$, dentro del marco del III Plan para la Igualdad de Oportunidades entre hombres y mujeres 1997-2000, que permite trazar un diseño aproximado del mapa institucional municipal en la materia a partir de los datos recabados en 32 municipios españoles.

Según el citado trabajo de campo, desde el punto de vista de las estructuras administrativas, cabe diferenciar tres grandes grupos organizativos en el ámbito municipal que se corresponde a su vez con tres tipos de municipios según la población: Concejalías de la mujer, Areas de la mujer integradas en Concejalías de servicios sociales y Concejalías de servicios sociales sin diferenciación orgánica.

A) Concejalía de la mujer. Esta fórmula organizativa es la seguida mayoritariamente por los municipios de más de 500.000 habitantes, municipios capitales de provincia de más de 200.000 habitantes y municipios de más de 50.000 habitantes de las coronas metropolitanas.

Dentro de este perfil municipal hay que distinguir las concejalías de nueva creación y las concejalías consolidadas, dado que existen grandes diferencias de actuación entre unas y otras. Las concejalías de nueva creación van parejas al importante esfuerzo de los municipios por elaborar sus propio Plan de igualdad, entendiendo por tal el diseño de estrategias puntuales para alcanzar la meta de la igualdad de sexos. En general se trata de proyectos que tienen como gran objetivo, integrar la política de igualdad en todas las actividades municipales, siguiendo la directriz de la transversalidad y a tal efecto, suelen trabar numerosos convenios con otras áreas municipales. Sus grandes objetivos de actuación podrían resumirse en los siguientes: investigación y acopio de datos, transversalidad, formación, sensibilización y demanda de participación y compromiso de la clase política y de la sociedad. En lo que concierne a su personal suele ser joven y muy comprometido con el pensamiento integrador e igualitario, con una filosofía de trabajo participativa, abierta e innovadora. Otra gran preocupación que mueve a estas nuevas concejalías es el asociacionismo, dirigiendo gran parte de sus esfuerzos a crear una red de asociaciones de mujeres con las que trabajar estrechamente y otorgarles estabilidad.

\footnotetext{
28 «Situación actual de las políticas y planes de igualdad en el ámbito municipal». Federación Española de Municipios y Provincias, Madrid, 2001.
} 
Por su parte, las concejalías de la mujer consolidadas, que en algunos casos arrastran un bagaje en la materia de más de quince años, típicas de los municipios de las coronas metropolitanas de más de 50.000 habitantes, constituyen el ejemplo de la experiencia y la madurez. Parten de un conocimiento del medio, llevado a cabo a través de estudios previos de las demandas de la población y una ímproba labor de investigación, así como de la transversalidad de la actuación. Las líneas de actuación ya no se dirigen a crear grandes programas de ideales o Planes de igualdad sino a articular programas «reales y asumibles». Seleccionan minuciosamente las materias sobre las que trabajar y elaboran planes sectoriales cuatrienales. También dan una gran importancia a las labores de divulgación, promoviendo campañas continuadas en el tiempo. En cuanto a la consagración de la transversalidad, ya no se apoyan en la firma de convenios puntuales sometidos a la voluntad de las partes sino en la asunción plena y sólida por todas las áreas municipales de las políticas de acción positiva a favor de la mujer y el deber general de integrar la misma en todos lo campos de la actividad política. Desde el punto de vista operativo, trabajan de forma coordinada y eficaz con sus recursos propios y suelen articular relaciones estables y firmes con otras instituciones a las que les exigen un fuerte compromiso con los planes de igualdad que diseñan.

B) Area de la mujer integrada en Concejalía de Servicios sociales. La creación de órganos diferenciados y especializados en la materia es la fórmula más habitual de organización local y la mayoritaria en los municipios de más de 50.000 habitantes que no forman parte de las coronas metropolitanas así como en los municipios de menos de 50.000 habitantes que forman parte de las coronas metropolitanas. También responden a este esquema la mitad de los municipios capitales de provincia de más de 200.000 habitantes.

Su característica principal reside en que cuentan con planes y políticas diferenciadas y específicas dirigidas a la población femenina enmarcadas dentro del Area de la mujer. Por lo que atañe a la labor llevada a cabo desde los órganos municipales, acostumbra a partir de un programa específico para las mujeres, diseñado por la Concejalía de pertenencia cuyos objetivos podrían resumirse en los siguientes puntos: a) Informar y asesorar a mujeres sobre cualquier cuestión; b) Promover el asociacionismo a través del asesoramiento técnico y vías de financiación con las que suelen trabar convenios de colaboración; y, c) Atención primaria o prestación de recursos básicos a las mujeres que están en mayores dificultades, con especial hincapié en el área de la violencia doméstica. A tal fin suelen crear un servicio especializado que cubre el asesoramiento legal, atención psicológica y socioeducativo, seguimiento y casas de acogida. 
En cuanto a la forma de trabajo, suelen confeccionar programas con una gran continuidad en el tiempo y tradición partiendo siempre de la transversalidad de la actuación, de modo que todas las acciones dirigidas a la mujer se conciben como un servicio integrado y asociado a otros servicios de bienestar social o de otras áreas municipales.

C) Concejalía de servicios sociales, sin diferenciación orgánica para estas actividades. A este esquema organizativo responden la mayoría de los municipios de menos de 50.000 habitantes. En general, estos municipios no cuentan con una política singularizada de actuación en el ámbito de la igualdad de la mujer, siendo una más de las muchas materias que suelen abarcar los programas de servicios sociales. Es pues, en los municipios más pequeños donde menos se realizan políticas diferenciadas de acción positiva a favor de la igualdad.

La metodología de trabajo de este tipo de municipios suele ser bastante primaria, descansando todas las acciones positivas en los servicios sociales de base. No existe personal especializado dedicado a estas actividades y desde el punto de vista ideológico se mueve en una filosofía conservadora que les lleva a pensar que no parece necesario realizar políticas activas o de discriminación positiva a favor de la mujer. Son renuentes a llevar a cabo actividades enfocadas expresamente a la igualdad de la mujer que, en general, suelen entender como privilegios que promueven la desigualdad de los sexos más que como ayuda a la igualdad misma.

No existen, por tanto, líneas de actuación dirigidas especialmente al colectivo de mujeres ni programas específicos a realizar. Todas las demandas o acciones positivas que se llevan a cabo tienen carácter puntual e individualizado y son atendidas de forma indiferenciada. Si llevan a cabo alguna línea de actuación, es porque la misma se impulsa desde la Comunidad Autónoma respectiva. Y de existir alguna, generalmente va dirigida a apoyar el asociacionismo femenino a través de subvenciones o cesión de locales con el fin de proceder a la delegación en aquéllas de las cuestiones relacionadas con las políticas de promoción de la igualdad que en su día hayan asumido. Estas asociaciones, por regla general, no tiene como fin primordial la lucha por la igualdad sino un corte más cultural, de ocio o educativo.

Como colofón a esta descripción, interesa destacar dos puntos. En primer lugar decir que algunos municipios han seguido avanzando en el ámbito organizativo creando órganos complementarios de asesoramiento y consulta. Es el caso de los Consejos municipales de la mujer, existentes en grandes municipios con un reconocido bagaje en este tipo de políticas 
públicas. Sirven de apoyo a las tareas municipales a la vez que materializan el elemento participativo ciudadano en la toma de decisiones municipales. Normalmente se acude a la fórmula de Consejos sectoriales que están constituidos, junto con los representantes de distintos grupos municipales, por miembros de las asociaciones de mujeres del municipio, sindicatos, asociaciones de vecinos y, en su caso, representantes de otras Administraciones públicas.

$\mathrm{Y}$, en segundo lugar, la valoración de la actividad y funcionamiento de este tipo de organizaciones destapa ciertos problemas y aciertos. En cuanto a los problemas, destacan los siguientes: la falta de recursos y el empleo abusivo de la figura subvencional dando primacía a actuaciones puntuales frente a programas compactados; la infravaloración política y social de la actividad llevada a cabo, reflejada en la desventajosa posición de partida de este tipo de política respecto de otras áreas municipales y la devaluación de la labor social frente a la económica; el sometimiento de la política de promoción de la igualdad a la coyuntura política de cada momento con la consiguiente falta de estabilidad, la excesiva burocratización y la ausencia de coordinación con otras convergentes en la materia; y, finalmente, el desbordamiento de los servicios sociales de los municipios más pequeños o desestructurados organizativamente, con exceso de funciones y defecto de personal.

Respecto de los aciertos, hay que señalar como más señeros la idoneidad de la creación de organismos con cierta autonomía en este campo así como la desconcentración de funciones en beneficio de la proximidad ciudadana y la cercanía física de los servicios ofrecidos; la profesionalidad, interés y satisfacción del personal que trabaja en estos servicios, tanto mayor cuanto más alto sea su grado de especialización; y la importancia del voluntariado para cubrir las demandas sociales de los usuarios de tales servicios.

\section{b) La articulación de funciones}

Desde la perspectiva de las funciones municipales, cumple destacar la apuesta por estrategias de igualdad planificadas sobre todo en los municipios de gran población (así, planes de igualdad de Barcelona, Granada, Jerez, León, Pamplona, Zaragoza, Santander, etc.) Sobre las políticas diseñadas ha de decirse que coinciden parcialmente con los objetivos poblacionales. A excepción de las áreas de empleo y violencia de género donde existe plena identidad con las demandas sociales, las restantes líneas 
estratégicas seguidas se inclinan por otra serie de actuaciones. Resumidamente, los puntos focales de la acción positiva en favor de la igualdad en el ámbito municipal discurren de acuerdo con el siguiente orden:

1. Área económica y de empleo: Es un área de actuación que ocupa siempre los primeros puestos en los objetivos de la acción pública, especialmente en los municipios entre 200.000 a 500.000 habitantes. Consideran la falta de empleo como una de las grandes causas de la desigualdad, por lo que el fomento de la incorporación de la mujer al mercado laboral constituye una de las grandes prioridades. Es generalizada la opinión de que sólo a través del empleo se logra alcanzar una negociación entre iguales y, de este modo, mitigar otras consecuencias que están directamente relacionadas con la falta de poder doméstico, como la violencia o la deficiente formación. De ahí, que se prime siempre este perfil en sus distintas vertientes (empresariado femenino, formación y capacitación profesional, reinserción laboral, etc.), ocupando un lugar destacado en la mayoría de los planes de igualdad municipales ${ }^{29}$.

2. Área de violencia de género: Junto con la anterior es la punta de lanza de todas las políticas de promoción de la igualdad, en estrecha consonancia con las deficiencias del sistema y las demandas de la población femenina.

3. Área educacional: Es un área de actuación preferente en los municipios menores de 200.000 habitantes pese a que el número de mujeres sin estudios es ostensiblemente menor al de otros municipios de corte rural o urbano. No obstante, el número de mujeres con estudios universitarios o de segundo grado desciende en esta franja poblacional.

4. Asociacionismo: el apoyo a las asociaciones de mujeres suele ser una constante de todos las políticas municipales. La razón de ello es que

\footnotetext{
29 Algunos Ayuntamientos han adoptado entre las distintas medidas de promoción de la igualdad en el ámbito laboral la posibilidad de inclusión de cláusulas de discriminación positiva en los pliegos de contratación con empresas. Así se contempla en el III Plan Municipal de igualdad de oportunidades entre mujeres y hombre del Ayuntamiento de Valladolid (2003-2006) en el que se exige la «inclusión en los pliegos de contratación con empresas, o bien en las instrucciones de valoración técnicas, de una cláusula en la que se valore, en igualdad de condiciones de las empresas presentadas, la contratación de mujeres». Sobre su licitud, ha tenido ocasión de pronunciarse la Junta Consultiva de Contratación Administrativa en el Informe 44/04, de 12 de noviembre de 2004, señalando que si bien tal cláusula «requeriría la modificación de la disposición adicional octava de la Ley de Contratos de las Administraciones Públicas, adicionando este supuesto al de los minusválidos y entidades sin ánimo de lucro en contratos relativos a prestaciones de carácter social o asistencial», «tal modificación no se estima procedente si se tienen en cuenta los criterios del Tribunal de Justicia de las Comunidades Europeas, de esta Junta y de la Directiva 2004/18/CE, de 31 de marzo de 2004».
} 
en muchas ocasiones el ente local las utiliza como plataforma de la acción municipal, dirigiendo toda la actividad de divulgación, apoyo y formación hacía éstas.

5. Área de salud: los municipios de más de 50.000 habitantes suelen dedicar gran parte de sus esfuerzos al área sanitaria en especial a los ámbitos de la ginecología preventiva, pediatría, control de natalidad, nutrición, geriatría y atención primaria.

6. Área lúdico-formativas: en los municipios de menos de 50.000 habitantes constituye una de las actividades más desarrolladas por los servicios sociales sin organización diferenciada, que algunas veces va acompañada de la descentralización de las mismas en áreas rurales con el fin de permitir el acceso a las mujeres de este entorno.

7. Atención a mujeres en situación de marginación: aparecen en el último lugar de atención de las políticas públicas y normalmente van dirigidas a familias monoparentales pertenecientes a minorías étnicas, chabolistas e inmigrantes.

En cuanto a la colaboración institucional articulada para llevar a efecto estas políticas de promoción, hay que destacar los distintos Institutos de la mujer, estatal y autonómicos, a los que se les suele demandar medios económicos, asistencia técnica y vincular sus políticas propias.

Como cierre de esta descripción, resta decir que en el ámbito provincial, la cooperación con los municipios en la realización de esta labor así como ausencia de políticas expresas en materia de igualdad son la tónica dominante en las Diputaciones Provinciales españolas. 